\title{
On the Innovative Way and System Demand for the Development of Teachers of Professional Courses in Higher Vocational Colleges in the Internet Era
}

\author{
Lihuan Liu*, Jiang Cen, Huifang Xiao \\ Water Conservancy Department \\ Hunan Polytechnic of Water Resources and Electric Power \\ Changsha, Hunan Province, China
}

\begin{abstract}
Teachers of professional courses in higher vocational colleges have dual attributes of higher education and professionalism. Under the background of Internet plus era, it is necessary to innovate the path of the development of professional course teachers in higher vocational colleges in order to meet the expectations of various subjects on an academic career. From the perspective of bottom-up vision, this paper proposes a new path for the development of professional course teachers in higher vocational colleges. On the premise of clarifying their orientation of academic career, it is necessary to strengthen their subject consciousness, actively carry out academic teaching and cultivate information-based teaching quality. On this basis, their development puts forward some demands on the system, which requires the government to design the top-level system for the development of teachers of professional courses in higher vocational colleges and formulate development standards. Higher vocational colleges should establish an internal subject symbiosis system suitable for the development of professional course teachers, carry out classified management on professional course teachers, build academic development team and reform its evaluation system.
\end{abstract}

Keywords-teachers' development, teachers of professional courses, academic career, internal subject symbiosis system, higher vocational colleges

\section{INTRODUCTION}

Teachers of professional courses in higher vocational education are the most important component of higher vocational education. Their belief, value, academic level and mental state will directly affect the efficiency and benefit of higher vocational colleges, and fundamentally influence the academic productivity and academic ecology of the higher vocational education system. Their development boasts of dual attributes of higher education and professionalism. "Technological pedagogical content knowledge (TPACK)" represents the biggest difference between vocational teachers and subject experts or ordinary educators. Therefore, only by following the academic nature of higher education system and education law, innovating their development path and clarifying the institutional appeal of "Internet plus vocational education" can we effectively realize the development of professional teachers in higher vocational education and promote its sustainable development as a whole.

\section{The CONTENTS OF THE DEVELOPMENT OF TEACHERS IN HigHER VOCATIONAL COLLEGES}

The development of the teachers in higher vocational colleges includes theoretical learning and practice in various ways so that their professional level can increasingly improve [1]. Their development is based on teaching and scientific research and aims at enhancing academic professional quality. The concept of "teachers in higher vocational colleges" involves both individual teacher and group teachers. They are both independent ones and the member of the academic community as well as higher vocational institutions. In addition to clarifying academic goals and focusing on academic development, they should take the goal of the group into consideration and attach importance to the study, performance and development, etc.

The main contents of the development of teachers in higher vocational colleges [2] include: getting more familiar with the concept of higher vocational education; changing the role and responsibility of education; improving the awareness of teaching ability; changing the attitude towards teaching and evaluation; enhancing knowledge and skills in teaching, research and management; developing relevant teaching knowledge and skills; improving behavior in educational management and curriculum development; acquiring the skills of curriculum development; increasing the passion and charming of teaching, effectively analyzing teaching and teaching methods, improving education technology and changing teaching methods; improving the learning atmosphere and developing student-centered teaching; forming a good teaching attitude and cooperative attitude; increasing the ability of cooperative teaching and the ability and confidence in teaching decision-making, and becoming more aware of individual strengths, weaknesses and limitations; improving teaching efficiency and performance.

Their development symbolizes the responsibility of colleges, governments and even social organizations. It needs strong external promotion, which consists of academic organizations where teachers work as well as government organizations and other social organizations or individuals. It includes both relatively specific development projects and sustained and stable support and service [3]. 


\section{ThE DILEMMA OF THE DEVELOPMENT OF PROFESSIONAL TEACHERS IN HigHER VOCATIONAL COLLEGES}

Teachers of professional courses in higher vocational colleges concerned about not only the cultivation of students, but also the improvement of their own teaching and research ability. However, at present, the platform of teaching and research for vocational education is not perfect. The front-line teachers of professional course lack enthusiasm in teaching and research, and their ability development is not balanced. The ecosystem of vocational education and research is still under construction and transformation, which is mainly reflected in the following aspects. Some teachers participate in scientific research activities only for obtaining professional titles which leads to the research objects fragmented and scattered without systematic research projects; others engage in teaching and research activities by themselves without team support, which causes great difficulty in teaching and research without sustained development, thus having little effect on the promotion of the reform on higher vocational education and teachers being unable to better adapt to the requirements of high-quality higher vocational colleges and professional (group) construction and connotation development.

There are several reasons for colleges' poor performance in teaching and research. Firstly, they lack frontline instructors and helpers. The reason why many teachers of professional courses in higher vocational colleges do not make progress or have little progress in research is that they are lack of cognition or attention. Without guidance in this aspect, when encountering difficulties, they will not get assistance, which slows down or interrupt the research. This is also the essence and necessity for higher vocational colleges to devote themselves to the construction of scientific research teams.

Secondly, teachers in higher vocational colleges are overloaded with daily teaching tasks. Many teachers not only have too many classes, but also too many different courses in each semester, leaving them insufficient time and energy for scientific research. Under the current environment, they must integrate ideological and political elements into their course in a nature way in order to meet the fundamental requirements of education. Therefore, they need to spend enough time in improving their political quality and finding appropriate cases and integration points. In addition, the requirements of information technology for higher vocational education also force them to learn more information channels, so that students can learn or contact with the most advanced technology. In the meantime, front-line professional course teachers must constantly update their professional knowledge to make professional courses more valuable. Additionally, they are busy with a large number of teaching competitions, practical training and skill inspection and so on.

\section{The PATH FOR THE DEVELOPMENT OF TEACHERS OF} Professional COURSES IN Higher VocATIONAL COLLEGES

There are three main bodies that determine the development of teachers of professional courses in higher vocational colleges: teachers of higher vocational colleges, higher vocational colleges, and the government. Among them, teachers of professional courses in higher vocational colleges are the main body of development and the internal factor that determines the development effect. Generally speaking, there are two kinds of visions to clarify the values and appeals of various subjects. This paper adopts bottom-up vision to innovate the path, that is, to explore the path of the development of teachers in higher vocational colleges from the perspective of vocational teachers, as shown in Fig. 1.

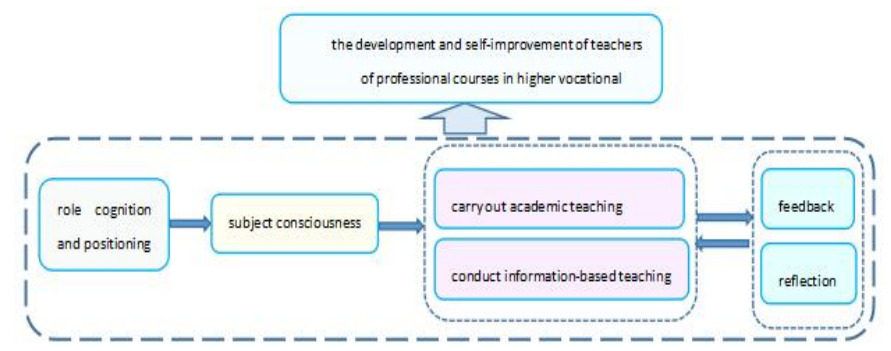

Fig. 1. The path of the development of teachers of professional courses in higher vocational colleges

\section{A. Forming a rational cognition on the characteristics of the role of teachers of professional courses in higher vocational colleges}

The occupation of professional course teachers in higher vocational colleges is comprehensive with multiple roles. The primary task of their development is to make clear the rational cognition of their own occupation, determine what kind of occupation they are engaged in, what kind of role they are developing, and what value and development vision they are pursuing. Their work is academic [4]. Their development has gradually shifted from professional teaching to teaching research, scientific research, social service and other aspects.

It is necessary for them to strike a balance among multiple roles before clarifying the rational cognition of professional roles [5,6]. Teachers of professional courses in higher vocational colleges hope to meet internal and external expectations. They should not only complete a large number of teaching tasks to meet external expectations of daily work, but also improve scientific research output to meet internal expectations of their own development. At the same time, most of them invest a lot of time and energy in social services and various competitions in the hope of improving their professional titles. From the perspective of the system, the requirements for their workload, the proportion of evaluation on scientific research, and the requirements for the professional title all have an impact on how they balance among multiple roles.

In addition to balancing multiple roles, they also face role transformation. Against the backdrop of Internet plus, their role has undergone great changes. Teachers are no longer the possessor or giver of educational resources, nor the disseminator of knowledge, but the organizer of teaching resources and the manager and guider of student learning. Their ability system and presentation include not only highly specialized knowledge, but also ability in management, analysis, execution and communication, so as to meet the actual needs of higher vocational teaching. Traditional cramming teaching is not suitable for contemporary higher 
vocational students. Classroom teaching should pay more attention to the process and ways of teaching in order to help students better complete their study. And teachers should acquire students' dynamic study information from the Internet real-time assessment data, guide them individually in accordance with the big data, encourage them to think boldly, work hard and innovate vigorously.

\section{B. Strengthening subject consciousness and developing self- improvement ability}

Teachers of professional courses in higher vocational colleges should enhance subject consciousness, emphasize the internal demand of value and regard development as the internal demand of teachers, which is the internal demand for their independent development, self-transformation and selfrealization. Additionally, it should also develop a symbiotic relationship with higher vocational colleges and the government. We can not regard them as management and implementation objects, affecting their enthusiasm, initiative and creativity.

As the main body of development, teachers of professional courses in higher vocational colleges should make clear "what type of teachers they should develop", "how to develop" and "to what extent do they develop". As for "what type of teachers they should develop", it has obvious personalized characteristics. According to their own responsibilities, needs, development goals and abilities, they should determine the subjects of scientific research, teaching, competition and social service projects. After identifying these issues, it is necessary to clarify "how to develop". It is essential to select the most valuable development resources and adopt the most suitable development mode in combination with the running orientation and development goal of the higher vocational colleges, as well as the foundation, advantages and disadvantages of the colleges themselves, so as to encounter fewer or zero difficulties in the process of realizing the development goal. Meanwhile, it is indispensable to balance and adapt to the development needs of higher vocational education in accordance with the current society and keep the pace with the times with great foresight to formulate career planning and make contributions to the development of the whole society and the times, hence pursuing personal and social value.

\section{Actively conducting academic teaching}

The overall level of education and scientific research of professional course teachers in a higher vocational college is the premise, foundation and driving force of education and teaching reform in the college, which determines to what extent they can achieve in the aspect of majors (group) construction and college development. Through the effective summary, analysis and statement of views of the experience and lessons of the development in higher vocational education at home and abroad by educational scientific research, it can reflect their motivation and ability of self-improvement from a certain level.

The expansion of the enrollment for higher vocational colleges in 2019 marks the popular stage of higher vocational education. At this time, higher vocational colleges have attracted more attention from society. And the teaching quality of higher vocational education has become a social problem, which inevitably reveals the contradiction between higher vocational teaching and scientific research. Thus, it is inevitable to develop academic teaching.

Academic teaching is a basic approach to develop the teaching for professional course teachers in higher vocational colleges, which requires them to pursue academic rational spirit in teaching concept, integrate the process and results of academic activities in teaching mode and emphasize continuous reflective practice in the teaching process. They should constantly review their own teaching. They should neither satisfy with the existing experience in teaching framework, nor blindly follow the regulations set by the management personnel at all levels, but explore continuously the teaching law and its development stages and characteristics, thus endowing the teaching with true academic core value and behavioral paradigm and enabling the academy to closely relate with its positioning and the role of talents cultivation have education significance.

\section{Taking the initiative to cultivate information teaching quality}

Under the background of the era of Internet plus, students of the higher vocational colleges were born and raised in the digital age. They have a particularly strong ability in learning information technology. Thus, teachers of higher vocational colleges must become the learners in the era, constantly update their information quality, adopt the information-based teaching mode and method and integrate information technology into their daily education and teaching. By doing so, it can better stimulate students' enthusiasm and initiative in learning. Because of its strong operability, information teaching is quite suitable for higher vocational teaching and the characteristics of "hands-on operation" and "practical skills". Teachers should take the initiative to use the big data of Internet plus to support teaching reform and decision-making in teaching and carry out effective teaching reform and practice by collection, statistics, analysis, management and exploration of data in specific teaching practice.

However, teachers' information teaching quality is not formed in a short time. It requires a relatively long time to develop quality. The formation of information quality is a process of teachers' independent development as well as joint cultivation of colleges and superior departments. The main approach is to promote the training of teachers' ability in information teaching. "Internet plus" teaching mode of training is adopted, which means that teachers can gain technological support for on-the-job training and network training. Thus, they can arrange their training time and place in a flexible way and solve their own problems according to their needs anytime and anywhere so as to improve their teaching ability in information technology. In addition, they can also rely on online learning platforms to form an alliance cooperative development model and a learning community with teachers of related disciplines in order to learn new technologies and skills together[7,8]. 


\section{THE APPEAL OF THE DEVELOPMENT OF TEACHERS IN HighER VOCATIONAL COLLEGES TO THE SYSTEM}

In the long run, the development of higher vocational colleges and the competition among them seems the competition of resources and talents, but in fact, it is the competition of the development system. Because the system is the most core element to attract and cultivate talents, promote the flow of resources and give full play to the role of talents and resources, which determines the flow of talents and resources[4]. Without an excellent system for the development of teachers in higher vocational colleges, there will be no outstanding teachers, and it is difficult to build an excellent higher vocational college.

As a basic activity in the academic field of higher vocational colleges, the development of professional course teachers has its own uniqueness and difficulty to reach from outside. Their development is characterized by academics, taking "advanced knowledge" as the research object and vocational students as the service object. It has its own stability and a high degree of individuation. There are some aspects that are difficult to reach from outside. Additionally, there are some aspects beyond the management of superior leaders. Their development does not simply depend on the government's policy. Internal and external institutional makers are not the only one to blame. This requires that system makers reach to the interior of the development of higher vocational teachers to understand all kinds of main body and their behavior, know what teachers do in their daily work, observe their development status, understand their development needs and stage of development and form a top-down observation and research and seek truth from facts, thus making policy accordingly.

\section{A. Strengthening the leading role of system}

1) Designing a top-level system for teachers of professional courses in higher vocational colleges.

The significance and importance of the development of professional teachers in higher vocational colleges should be placed on the strategic height of the development of higher education. It should design a top-level system for their development. Thus, it is necessary to comprehensively consider the integrity of the training stage, deepen their hierarchical and classified development, guide new teachers and young teachers to pay attention to the continuous improvement of professionalism and the accumulation of teaching experience and lay a solid foundation. Meanwhile, it should guide middleaged teachers to develop deeply in their professional field and become experts in the professional field. At the same time, it should pay attention to the improvement of teaching organization and management, strengthen the consciousness of team building, and activate the vitality of professional course teachers. In addition, it should value their emotion, especially the improvement of the sense of value and gain of career and bring humanistic factors into the system of professional course teachers' development

2) Forming the standard for the development of teachers of professional courses in higher vocational colleges

With the expansion of the enrollment of higher vocational colleges, the government should strengthen its specific guidance and management of colleges and universities. Higher vocational colleges should focus on teaching and practice and pay full attention to the improvement of academic level and practical ability of teaching, so as to guarantee the reputation and social status of higher vocational colleges. But meanwhile, due to the nature of scientific research itself, its role does not change with the nature of colleges and universities. In particular, for professional course teachers, their professional attainments are the fundamental guarantee of classroom teaching quality. Therefore, higher vocational colleges should emphasize scientific research at the same time. The balance and standard of these two aspects require the macro-guidance and regulation of the government.

The government should play a guiding role in the key aspect of the development of teachers, study and formulate national basic standard of performance evaluation for the hierarchical and classified development oriented towards teachers in higher vocational colleges, and provide the basic index reference system of performance evaluation for teachers of different levels, types and categories of subjects from the national level. The government assumes the supervision function after the decentralization and establishes the mechanism of power balance and supervision under the coordination of multiple bodies.

\section{B. Building a symbiotic system}

Higher vocational colleges themselves should carry out a series of resource integration and organizational reform to build an internal subject symbiosis system suitable for the development of professional course teachers. Colleges and departments should actively strengthen contact with the society, become the main body of communication for teaching, scientific research and social services, effectively increase channels for teachers to express their interest demands and participate in academic decision-making and stimulate the internal vitality of higher vocational colleges. If they fail to attach importance to it and let such development mode develop, it will be difficult to deepen teachers' development activities at the school level and stimulate their enthusiasm to participate in professional courses will be greatly reduced.

\section{1) Classifying teachers of professional courses in higher} vocational colleges

At present, higher vocational colleges have promoted the classified management on professional course teachers in accordance with the differentiation of academic profession and set up different posts, such as teaching-oriented, researchoriented, teaching-oriented, and social-service-oriented posts. Every field has its master. The rationality of this kind of reform is obvious and some experience and effects have been made. However, there are still some problems such as insufficient elaboration of post responsibilities, incomplete post assessment, and unclear development path of different posts, which lead to blind development of professional course teachers. To what degree can we solve these problems? It directly determines whether teachers can choose suitable posts according to their own development expertise and academic aspirations, and achieve real development in these posts. 
2) Building teams for the development of teachers of professional courses in higher vocational colleges

Team building is the only way to the professional development of teachers in higher vocational colleges. Through team building of the teachers, resources from teaching culture and scientific research culture in colleges are integrated to provide support for the development of teachers in teaching and discipline. The professional course teachers in higher vocational colleges are characterized by "professional", with a high level of professionalism and standardization. It is not enough to rely solely on the accumulation of personal experience and self-reflection for their growth. It needs a specific team and organizational mechanism to provide support for them. In actual work, in order to gain experience and inspiration from other peers, they have a strong practical demand for teamwork. They will participate in not only in various teams, but also independently seek teams needed for their career development. However, the current teachers' teams in higher vocational colleges are mostly divided into teaching teams and scientific research teams on purpose, which leads to the conflict between teaching culture and scientific research culture in colleges and universities and requires the strength of the team to coordinate and solve it.

3) Reforming evaluation system of teachers of professional courses in higher vocational colleges

The evaluation system of teachers of professional courses in higher vocational colleges directly determines their recognition and sense of mission and determines their enthusiasm and initiative. In terms of the evaluation, due to their academic attributes, it is appropriate to change the evaluation subject from administrative subject to academic one. In terms of the reward system, the key point is to produce positive feedback effect, demonstration effect and leading effect on professional course teachers and form the belief and cultural system of professional course teachers. Positive feedback, as an incremental benefit of the system, is the dynamic source of institutional innovation in the development of professional teachers in higher vocational colleges.

\section{CONCLUSION}

The development of teachers of professional courses in higher vocational colleges is based on correct cognition and positioning of their role. They should pay attention to the higher education of vocational and professionalism, improve their subject consciousness, attach importance to their demand for interior value and develop a symbiotic relationship with higher vocational colleges and society.

In order to guarantee the development of teachers of professional courses in higher vocational colleges, government and higher vocational colleges are required to guide the system, seek for the establishment of a symbiotic system, design toplevel system for their development, formulate the standard and carry out macro-control and guidance. Additionally, the colleges should carry out the classified management on themselves, build teams for the development of teachers, reform their appraisal system and promote their development.

\section{REFERENCES}

[1] Pan Maoyuan, Zhu Leping. The logic of Policy Change in Higher Vocational Education: from the Perspective of Historical Institutionalism [J]. Educational Research,2019(1):23-42

[2] Zhou Haitao, et al, On the Development of Teachers in Colleges and Universities: Theory and Practice [M]. Beijing: Educational Science Publishing House, 2015

[3] Zhu Yanjun, Academic Teaching for Teachers in Colleges and Universities-Theoretical Logic and the Path for System[M]. Shanghai: Shanghai University Publishing House, 2017

[4] Jiang Chao, On the Innovative Research on the System for the Development of Teachers in Colleges and Universities-Based on the Perspective of New Institutionism[D], Shanghai: East China Normal University, 2018

[5] Kang Weiwei, On the Professional Development of Teachers in Institutions of High Learning Under the Background of Big Data[J]: Education and Vocation, 2016(08).

[6] Li Guocheng, Xiang Yanlin, On the Professional Development of Teachers in Higher Vocational Colleges Under the Background of Big Data: Challenge, Connotation and Path[J]. Vocational Technology, 2019(18):95-98

[7] Fu Mengchen, Research on the Path of the Improvement of InformationBased Teaching Ability for Teachers in Higher Vocational Colleges[J]. Journal of Hubei Adult Education Institute, 2019( 25):34-37.

[8] Wang Lingling, Song Xiaoqing, Research on the Improvement of Informational Quality for Teachers in Higher Vocational Colleges Under the Background of "Internet Plus"[J]. The Chinese Journal of ICT in Education, 2019( 06):73-76. 